V.13, n.1:2017.

\title{
UM MARCO PARA A HISTÓRIA EDUCACIONAL MATO-GROSSENSE: A CRIAÇÃO DO APRENDIZADO AGRÍCOLA GUSTAVO DUTRA
}

\author{
Prof. Dr. Abimael Antunes Marques \\ Instituto Federal de Mato Grosso/Campus São Vicente \\ E-mail: abimael1958@gmail.com \\ Prof. Dr. Geraldo Inácio Filho \\ Universidade Federal de Uberlândia \\ E-mail: gifilho@ufu.br
}

RESUMO: O presente trabalho faz uma pequena retrospectiva sobre a trajetória da instituição educacional denominada Aprendizado Agrícola Gustavo Dutra, criada pelo Governo Federal nos idos de 1943 no município de Santo Antônio do Rio Abaixo, no Estado de Mato Grosso.

Palavras-Chave: Mato Grosso. Ensino agrícola. Educação Profissional

\section{A MARK FOR THE EDUCATIONAL HISTORY OF MATO GROSSO: THE FOUNDATION OF THE AGRICULTURAL APPRENTICESHIP GUSTAVO DUTRA}

\begin{abstract}
The currently work does a short retrospective on the educational institution named agricultural apprenticeship Gustavo Dutra, created for the Federal Government back in 1943, in the county of Santo Antônio do Rio Abaixo, in the state of Mato Grosso.
\end{abstract}

Key-words: Mato Grosso. Agricultural education. Professional education

\section{INTRODUÇÃO}

Nos idos de 1943, foi criado pelo Governo Federal, no município de Santo Antônio do Rio Abaixo, Estado de Mato Grosso, o Aprendizado Agrícola Gustavo Dutra, subordinado à Superintendência do Ensino Agrícola e Veterinário do Ministério da Agricultura.

Justino Magalhães, ao esclarecer sobre a construção histórica de uma instituição educacional, acolhe a matéria da seguinte maneira:

A construção da história de uma instituição educativa visa conferir uma identidade cultural e educacional. Uma interpretação do itinerário histórico, à luz do seu próprio modelo educacional. A história de uma instituição educativa constrói-se a partir de uma investigação coerente 
V.13, n.1:2017.

e sob um grau de complexificação crescente, pelo que, à triangulação entre os historiais anteriores, à memória e o arquivo, se haverá de contrapor uma representação sintética, orgânica e funcional da instituição - o seu modelo pedagógico (MAGALHÃES, 1999a, p. 72). 
V.13, n.1:2017.

A construção da história dessa instituição educacional já foi objeto de estudo do autor quando da realização do seu curso de mestrado (2005). Naquele momento, buscou-se aprofundar no arquivo da própria instituição. Nesta nova etapa, não será diferente. $\mathrm{O}$ arquivo institucional será, mais uma vez, a base para este estudo, pois, de acordo com Justino Magalhães,

Se a primeira aproximação à história de uma instituição educativa se obtém a partir de um olhar externo, é, todavia à medida que o historiador mergulha na sua interioridade a partir de informações que lhe permitam uma análise sistemática, sob um mesmo conjunto de fenômenos, que o historiador estabelece hipóteses-problema e esboça um sentido para as suas investigações. Uma compreensão, uma hermenêutica que se processa de forma gradual e para a qual os primeiros contactos com o arquivo são fundamentais. $\mathrm{O}$ arquivo, tal como se encontra organizado, quando o investigador inicia o seu trabalho, constitui uma informação multidimensional e uma representação muito aproximada da evolução, das dimensões e do sentido que a instituição empresta ao seu quotidiano e ao seu destino. $\mathrm{O}$ arquivo é uma imagem complexa, mas muito sugestiva, capaz de fornecer ao investigador percepção que constitui uma iluminação sobre a realidade a historiar e sobre o processo epistémico para fazê-lo (MAGALHÃES, 1999a, p. 70).

Para Justino Magalhães, o contato do historiador com o arquivo é de fundamental importância para que ele possa dar sentido às suas investigações. Nesse campo investigativo, Ester Buffa também nos auxilia quando estabelece algumas categorias de análise das instituições educacionais:

[...] procuramos investigar o processo de criação e de instalação da escola, a caracterização e a utilização do espaço físico (os elementos do prédio, sua implantação no terreno, seu entorno e acabamento), o espaço do poder (diretoria, secretaria, sala dos professores), a organização do uso do tempo, a seleção de conteúdos escolares, a origem social da clientela e seu destino provável, os professores, a legislação, as normas e a administração da escola. Essas categorias permitem traçar um retrato da escola com seus atores, aspectos de sua organização, seu cotidiano, seus rituais, sua cultura e seu significado para aquela sociedade (BUFFA e NOSELLA, 1999, p. 27).

Acredita-se que esse é o melhor caminho a ser seguido. $\mathrm{O}$ arquivo do antigo Aprendizado Agrícola Gustavo Dutra encontra-se em estado deplorável, abandonado. 
V.13, n.1:2017.

Para esclarecer aspectos não revelados pelos documentos oficiais, buscamos as fontes orais. Entrevistas com ex-professores e egressos do antigo Aprendizado Agrícola

Gustavo Dutra foram realizadas com o intuito de aclarar os aspectos nebulosos da pesquisa e até mesmo suprir a falta de documentos.

Começa-se mostrando que algumas mudanças de nomenclatura compõem o histórico da instituição: de Aprendizado Agrícola Gustavo Dutra para Escola de Iniciação Agrícola Gustavo Dutra em 22 de janeiro de 1947 e, posteriormente, em 05 de novembro de 1956 para Escola Agrícola Gustavo Dutra, mantendo sempre suas características e o sucesso das atividades educacionais, integrando e promovendo o crescimento de toda a rede de ensino profissionalizante do País. O reconhecimento social e a procura popular pelos cursos profissionalizantes aumentavam de acordo com o desenvolvimento econômico da nação e a demanda de mão de obra qualificada em todos os setores econômicos, em especial da agricultura, no Estado de Mato Grosso (MARQUES, p. 4, 2013, mimeo).

Uma nova etapa desse processo deu-se no dia 13 de fevereiro de 1964, quando o ano letivo começou com duas novidades para a comunidade estudantil e demais interessados em ampliar e dar sequência à formação acadêmica profissional. $\mathrm{O}$ agora Ginásio Agrícola Gustavo Dutra oferecia, na sua matriz curricular, o nível ginasial de ensino e, no exercício da democracia, recebia, de portas abertas, o ingresso da primeira geração, de tantas outras, do gênero feminino, que enfrentou a sociedade machista e matriculou-se em cursos e instituições antes frequentadas e dominadas apenas por homens. Embora o ginásio só tenha permitido a entrada do sexo feminino em suas fileiras, praticamente, 20 anos após a sua inauguração, não se pode esquecer que as mulheres conquistaram esse direito nos anos setecentos através da reforma pombalina.

Novos alunos, novas perspectivas e consequentemente novos resultados qualitativos e quantitativos. Somados ao ininterrupto crescimento de toda a rede de ensino profissional federal, esses resultados permitiram, ao Ginásio Agrícola Gustavo Dutra, galgar e alcançar, no dia 13 de março de 1978, o oferecimento do curso Técnico 
V.13, n.1:2017.

em Agropecuária integrado ao ensino médio, transformando novamente a realidade social da região. Isso atraiu ainda mais estudantes e famílias de todo o Estado de Mato Grosso e regiões vizinhas que, somado aos antigos moradores, internos e funcionários da escola compuseram a comunidade e mesmo a Vila de São Vicente (MARQUES, p.5, 2013.mimeo)

Mediante a realidade e constante expansão dos serviços oferecidos pelo Ginásio Agrícola Gustavo Dutra, as adequações eram inevitáveis e novamente a nomenclatura foi modificada. No dia 04 de setembro de 1979, a instituição passou a chamar-se Escola Agrotécnica Federal de Cuiabá - MT, nome que divide mérito com Escola Agrícola de permanecer forte no imaginário e memória coletiva da sociedade mato-grossense, que se remetem e identificam-se com o sucesso e prestígio conquistado pela instituição no período e decorrer de sua trajetória (MARQUES, p. 5, 2013, mimeo).

Outra etapa que demarcou grandes mudanças institucionais e deu continuidade ao processo de expansão, inclusão e transformação social foi o advento, no ano de 2000, do curso de nível superior de Tecnologia de Alimentos. Dentro da nova perspectiva, no espaço de dois anos, precisamente em 16 de agosto de 2002, por decreto do Governo Federal, a Escola Agrotécnica Federal de Cuiabá - MT passou a ser uma autarquia institucional autônoma. Isso, na prática, representou uma revolução irreversível na estrutura organizacional, administrativa e gestacional, permitindo que o agora Centro Federal de Educação Tecnológica - Cefet/Cuiabá passasse a oferecer cursos de todos os níveis e modalidades. A nova estrutura institucional trazia consigo ainda mais novidades e perspectivas de crescimento, promovendo um positivo ciclo vicioso de desafios e transformações (MARQUES, p. 6, 2013, mimeo).

O Cefet/Cuiabá, bem como toda a sua história, marcou e inseriu-se na identidade de diversas gerações que carregam o orgulho de ter participado da construção da renomada instituição educacional, centro de referência em educação e inclusão profissional e social do Estado de Mato Grosso. A instituição, juntamente com o governo federal, promove e implementa cursos que visam atender principalmente o núcleo excluído e carente de oportunidades da sociedade, mantendo o caráter inicial e 
V.13, n.1:2017.

norteador das primeiras escolas técnicas agrícolas, oferecendo educação pública de qualidade. A exemplo do Programa de Educação de Jovens e Adultos - Proeja, lançado pelo governo e executado no Cefet/Cuiabá a partir de 2007, com turmas presenciais e semipresenciais, permitindo que pequenos agricultores e suas famílias pudessem retomar o estudo formal sem abandonar o campo, a terra e o trabalho que lhes garantissem a qualidade de vida e dignidade merecidas por quem sustenta a nação com o suor de seu labor (MARQUES, p. 8, 2013, mimeo).

Sempre pioneiro e atento às possibilidades e oportunidades da realidade e conjuntura nacional, o Cefet/Cuiabá participou e contribuiu com as discussões e mesmo composição do quadro de gestores e servidores que impulsionam e alavancam a atual e possivelmente a maior expansão e transformação da Rede Federal de Educação Profissional e Tecnológica, que elevou os Cefets e toda a rede oriunda dos precursores Aprendizados Agrícolas e Escolas de Aprendizes e Artífices a Institutos Federais de Educação, Ciência e Tecnologia - IFs, equipando-os para atuarem como universidades, preparando e qualificando profissionais de todos os níveis e modalidade, expandindo e abrindo campi onde houver demanda social e econômica, respeitando as vocações, especificidades e cultura regional, promovendo inclusão, transformação, satisfação e mesmo felicidade, por meio da difusão dos saberes, do conhecimento e da prática humana de educar e produzir cultura (MARQUES, p. 10, 2013, mimeo).

\section{UM MARCO DO SÉCULO PASSADO: A CRIAÇÃO DO APRENDIZADO AGRÍCOLA GUSTAVO DUTRA}

A nossa pesquisa constatou que, até 2007, foram produzidas três dissertações sobre essa escola. A primeira (1997) foi produzida por Luciane Neuvald e versou sobre o Ensino agrícola no período populista - 1943/1964: o Aprendizado Agrícola de Mato Grosso e teve como objeto A Modernização da Agricultura Mato-Grossense. A segunda (2005) foi produzida pelo próprio autor: Aprendizado Agrícola "Gustavo Dutra”: Seu Papel e Importância no Contexto Agrícola de Mato Grosso (1943-1947). Para o autor, a instituição é um diferencial na formação do trabalhador e um divisor entre a agricultura rudimentar e a agricultura que emprega técnicas e tecnologias mais elaboradas e que são adquiridas no interior da escola, enfocando o período de 1943 - 
V.13, n.1:2017.

1947. A terceira (2007) produção acadêmica é de Lindamar Etelvino Santos Soares, para quem o período de 1947-1956, da instituição é reflexo de uma rede de poder repressiva, disciplinar e normalizadora.

Para Luciane Neuvald, a criação do Aprendizado Agrícola em Mato Grosso foi a maior dádiva que o Estado Novo poderia proporcionar à população mato-grossense. 
V.13, n.1:2017.

Segundo a autora:

A maior dádiva do Estado Novo a Mato Grosso é a expressão utilizada pelo discurso oficial para se referir ao Aprendizado Agrícola "Gustavo Dutra", visto como um marco histórico da agricultura mato-grossense, na medida em que era considerado um divisor de duas épocas na vida rural de Mato Grosso: a extensiva, empírica e extrativa; e a racional, experimental e científica (NEUVALD, 1997, p. 1).

A mesma autora ainda nos diz mais ao comentar que:

O discurso da racionalização da agricultura reservava para a educação o papel de despertar nas populações campesinas uma "disposição" maior para a prática de uma agricultura "racional" e assim, um aumento da produção que viria acompanhada de uma melhoria das condições de vida, do aumento do consumo e de um ambiente favorável à industrialização do campo e da cidade. Por trás desse discurso estava implícita a ideia de que o atraso econômico e técnico eram efeitos do baixo nível cultural da população, valorizando-se como fator primordial para a industrialização da agricultura o conhecimento de novas técnicas, mais do que propriamente a existência de capitais para a implantação das mesmas (NEUVALD, 1997, p. 3-4).

Luciane Neuvald destaca a importância do aprendizado frente às novas exigências da agricultura, do ensino agrícola, da industrialização e do êxodo rural:

Tal fato implica em contemplar o Aprendizado Agrícola "Gustavo Dutra" tomando como base a relação entre o processo produtivo e o educativo, tendo em vista a definição dos papéis efetivamente desempenhados pelo mesmo a partir das novas exigências à agricultura e ao ensino agrícola com o processo de industrialização e com o aumento do êxodo rural e das demandas por educação. O estudo abrange o período populista, de 1943, quando é criado o educandário, a 1964, quando é rompido o pacto populista e a agricultura e o ensino voltado para a mesma passam a sofrer mais intensamente as influências da industrialização desse setor da economia (NEUVALD, 1997, p.4).

Complementando, Luciane Neuvald trata da problemática dos diferentes enfoques e significações das fontes utilizadas na sua pesquisa:

A problemática encontra-se no âmbito dos diferentes enfoques e significações atribuídas pelas fontes escritas (Jornal o Estado de MT, Mensagens e Relatórios dos Governadores e Interventores e a Revista 
V.13, n.1:2017.

Brasil Oeste) e a pesquisa oral, que foi utilizada tendo em vista a necessidade de lidar com os silêncios da história e de diminuir o peso 
V.13, n.1:2017.

das fontes escritas. Enquanto as fontes escritas e oficiais privilegiam o valor econômico-social do Aprendizado, onde a educação assume a função de melhorar as condições de vida do homem do campo ao possibilitar-lhe uma "disposição" maior para o emprego de novas técnicas; um outro sentido é encontrado na pesquisa oral, onde o elemento mais destacado pelos egressos para definir a importância do Aprendizado é a formação da personalidade através da estrutura disciplinar rígida (NEUVALD, 1997, p. 4).

O pesquisador Abimael Marques, em sua dissertação de mestrado, relata a luta do Estado pela criação do Aprendizado Agrícola e a demora do Governo Federal em atender à solicitação:

O governo de Mato Grosso lutou para que um Aprendizado Agrícola fosse instalado no Estado. O Governo Federal demorou a atender à solicitação, talvez pelo fato de ser Mato Grosso um Estado distanciado das regiões mais desenvolvidas do país ou, até mesmo, por não dispor de uma representação política forte. Porém, quando Getúlio Vargas planejou intervir no cenário mato-grossense, estimulando a pequena $\mathrm{e}$ média produção, criou em Mato Grosso um Aprendizado Agrícola, em parceria da União com o Estado (MARQUES, 2005, p. 44).

Abimael Marques enfoca o início do trâmite processual para a criação do Aprendizado, as suas características, a sua localização no Estado, as condições para a sua instalação e o orçamento destinado a sua construção. Ele conta que no dia 13 de junho de 1939, o ministro da Agricultura, Fernando Costa, solicitou, aos seus assessores, que preparassem um expediente sobre a construção de um Aprendizado Agrícola em Mato Grosso, o qual deveria ter as mesmas características de outro a ser construído no Estado do Pará. Abimael Marques complementa:

O Aprendizado deveria ser localizado no Município de Santo Antônio do Rio Abaixo, em terras a serem doadas pelo Estado de Mato Grosso. Em 19 de junho de 1939, o engenheiro-chefe J. M. Maciel enviou ao mesmo Ministro o orçamento e as plantas. O projeto inicial previa a construção de dois edifícios, sendo o primeiro destinado à administração e salas de aula, e o outro, para abrigar dormitórios e refeitório. $\mathrm{O}$ orçamento para as obras atingia o montante de 3.197.315\$000 (três mil, cento e noventa e sete contos e trezentos e quinze mil réis). No documento, o Ministro expôs, com clareza e visão administrativa, os motivos que justificaram a criação do Aprendizado Agrícola. Julgando que o projeto continha detalhes que indicavam que 
V.13, n.1:2017.

as construções teriam problemas futuros de manutenção, luxo excessivo e elementos supérfluos, o Presidente da República, Getúlio Vargas, determinou que o projeto fosse revisto e devolvido para posterior apreciação (MARQUES, 2005, p. 44-45).

Em seu trabalho, mais à frente, Abimael Marques traz o Decreto-Lei n 300 , de

2 de setembro de 1939, o qual estabelece a doação das terras para a instalação do Aprendizado Agrícola em Mato Grosso, uma das exigências estabelecidas pelo Governo Federal. Aqui, está na íntegra:

Pouco mais de dois meses após o despacho presidencial, o Interventor Federal Júlio Müller enviou ao Ministro Fernando Costa o traslado de escritura pública de doação, feita pelo Estado de Mato Grosso, de uma área de cinco mil hectares, localizada no local denominado São Vicente, distante $86 \mathrm{KM}$ do município de Cuiabá, para que ali fossem construídas as instalações do Aprendizado Agrícola. A escritura de doação é datada de 12 de setembro de 1939. O governo do Estado registrou pública e oficialmente essa doação no Decreto $\mathrm{n}^{\circ} 300$, de 2 de setembro de 1939, publicado no Diário Oficial de 3 de setembro do mesmo ano:

DECRETO-LEI n ${ }^{\circ}$ 300, de 2 de setembro de 1939.

Reserva uma área de terras, destinadas à instalação de um Aprendizado Agrícola, no lugar denominado "São Vicente", município de Cuiabá.

O Bacharel Júlio Strubing Müller, Interventor Federal no Estado de Mato Grosso, usando da atribuição que the confere o art. 181, da Constituição da República,

DECRETA:

Art. $1^{\circ}$ - Fica reservada uma área de terras, destinada à instalação de um Aprendizado Agrícola, no lugar denominado "São Vicente", município de Cuiabá, tendo os seguintes limites: ao Norte, a sesmaria "S. Antônio da Fartura, do Dr. Jonas Corrêa da Costa; ao Nascente, com terras da sesmaria "S. José"; ao Poente, com terras da sesmaria "Bom Retiro", de Firmino de Tal e outros; e ao Sul, com terras da sesmaria "Cupim", de Jorge Leite Pereira.

Art. $2^{\circ}$ - Revogam-se as disposições em contrário.

Palácio do Governo do Estado, em Cuiabá, 2 de setembro de 1939, $118^{\circ}$ da Independência e $51^{\circ}$ da República.

Júlio Strubing MüllerJ. Ponce de Arruda (MARQUES, 2005, p. 45- 
V.13, n.1:2017.

46).

Em sua pesquisa, Abimael Marques percebeu que houve um conflito de interesses quando da doação dessas terras pelo Estado de Mato Grosso à União. Á época, o Estado tinha a permissão da União para fazer a venda de terras devolutas. As terras doadas já haviam sido objeto de requerimento para compra há mais de um ano, conforme diz Marques:

Há exatamente um ano e três meses antes, Francisco Monteiro Sobrinho, desejando fazer a compra de um lote de terras devolutas, havia feito a seguinte petição:

\section{Repartição de Terras e Obras Públicas}

\section{Secção de Terras}

\section{EDITAL}

De ordem do Sr. Dr. Diretor, faço público, para conhecimento dos interessados, durante o prazo de trinta dias, a petição seguinte:

Exmo Sr. Dr. Secretário Geral deEstado.

Francisco Monteiro Sobrinho, desejando adquirir por compra, do Estado, um lote de terras devolutas, pastais e lavradias, com área aproximada de 2.000 hectares, no lugar denominado "São Vicente", município da Capital, vem com todo respeito requerer a V. Excia que se digne conceder-lhe por venda o referido lote, cujos limites são os seguintes ao Norte, a sesmaria "S. Antônio da Fartura, do Dr. Jonas Corrêa da Costa; ao Nascente, com terras da sesmaria "S. José"; ao Poente, com terras da sesmaria "Bom Retiro", de Firmino de Tal e outros; e ao Sul, com terras da sesmaria "Cupim", de Jorge Leite Pereira.

Nestes termos, P. Deferimento.

Cuiabá, 24 de junho de 1938.

(a) Francisco Monteiro Sobrinho

Secção de Terras, em Cuiabá, 11 de julho de 1938.

Sérgio Pereira Borges

Chefe de Secção (MARQUES, 2005, p. 45-46). 
V.13, n.1:2017.

Sobre esse mesmo conflito, Abimael Marques ainda complementa:

Percebe-se que as terras, objeto de compra do Sr. Francisco Monteiro Sobrinho, eram as mesmas que foram destinadas à União para a instalação do Aprendizado Agrícola. Qual terá sido a resposta do governo do Estado ao solicitante? A resposta do governo a uma petição dessa natureza era rápida. Infelizmente, não conseguimos essa resposta, pois o Diário Oficial do período não traz qualquer publicação referente ao assunto (MARQUES, 2005, p. 45-46).

Abimael Marques esclarece que, em julho de 1939, foi autorizada a construção do Aprendizado Agrícola e que o período de 1939 a 1943 foi destinado à construção dele:

Em 4 de julho de 1939, Getúlio Vargas autorizou a construção do Aprendizado Agrícola, nos novos moldes do projeto reformulado. Entre 1939 e 1943, a Companhia Construtora Pederneiras S. A. construiu os prédios que constavam no projeto original com as modificações sugeridas pelo Presidente da República (MARQUES, 2005, p. 47).

Segundo Abimael Marques, o Aprendizado Agrícola foi criado no dia 14 de abril de 1943, por meio do Decreto-Lei $\mathrm{n}^{\circ} 5.409$, o décimo segundo criado e gerido pela União. Abimael Marques ainda nos diz que o Aprendizado Agrícola só funcionou com a sua primeira turma a partir de 1945:

No dia 14 de abril de 1943, por força do Decreto-Lei $n^{0} 5.409$, o Governo Federal cria, no local denominado São Vicente, município de Cuiabá, Estado de Mato Grosso, um Aprendizado Agrícola, subordinado à Superintendência do Ensino Agrícola e Veterinário do Ministério da Agricultura, que recebeu o prefixo de $n^{\circ} 12$, ou seja, era o décimo segundo aprendizado sob a responsabilidade da União a ser criado no país. Embora instituído em 1943, o Aprendizado Agrícola só funcionou, de fato, a partir de 1945, quando ingressaram seus primeiros alunos. Nesse momento, sua denominação foi alterada para Aprendizado Agrícola Gustavo Dutra (MARQUES, 2005, p. 47).

Um fato interessante encontrado na pesquisa de Abimael Marques foi a nova denominação do Aprendizado Agrícola:

O nome "Gustavo Dutra" foi-lhe atribuído pelo Decreto-Lei $n^{\circ} 6.945$, de 12 de maio de 1944. Gustavo Dutra ocupou posição de destaque no cenário agrícola brasileiro, como Engenheiro Agrônomo, formado 
V.13, n.1:2017.

pela Escola Agrícola do Imperial Instituto Baiano de Agricultura, onde também exerceu a função de professor. Exerceu ainda a função de Diretor do Instituto Agronômico de Campinas e da Escola Superior de Agricultura e Medicina Veterinária. Enfim, foi uma personalidade de extrema importância na divulgação da causa agrícola no país (APRENDIZADO AGRÍCOLA GUSTAVO DUTRA, 1944, p. 1-6).

Em outro trecho de seu trabalho, Abimael Marques traz a localização geográfica do Aprendizado Agrícola e as razões que foram determinantes para essa localização:

Para a escolha da localização do Aprendizado mato-grossense, de acordo com os periódicos veiculados à época, foram levados em consideração os aspectos físico-geográficos, aliados ao clima ameno e favorável, à qualidade das terras e à posição estratégica, pois, assim posicionado, beneficiaria três zonas principais do Estado, quais sejam: a zona central, essencialmente agrícola, abrangendo os municípios de Cuiabá, Santo Antônio do Rio Abaixo, Nossa Senhora do Livramento, Poconé, Rosário Oeste, Diamantino e Cáceres; a zona leste, que abrangia os municípios de Araguaia e Herculânea; e a zona oeste, região predominantemente de criação de gado, que abrangia os municípios por onde passava a Estrada de Ferro Noroeste. A princípio, entendeu-se que a amizade que ligava o Interventor Federal Júlio Müller ao Presidente Getúlio Vargas, e a posição de destaque ocupada por Filinto Müller, como Chefe de Polícia da Capital Federal, e irmão do Interventor, foram elementos essenciais para que o Aprendizado fosse instalado na região norte do Estado, próximo à Capital, pois a parte sul já desfrutava de maiores índices de desenvolvimento econômico (MARQUES, 2005, p.47-48).

\section{O PODER DISCIPLINADOR}

A pesquisadora Lindamar Soares produziu a dissertação intitulada Escola de Iniciação Agrícola Gustavo Dutra: o poder disciplinar no contexto do ensino agrícola de Mato Grosso (1947-1956). É um importante trabalho. A pesquisadora traz à tona, principalmente, a dureza com que a escola disciplinava seus alunos. Em determinado trecho da sua pesquisa, Lindamar Soares destaca:

As minúcias são deixadas de lado principalmente por parte do homem comum. As pequenas coisas ficam tão minúsculas como se não existissem. O homem, também, que adentra a Escola de Iniciação Agrícola "Gustavo Dutra", no século XX, advindo do garimpo, das lavouras, das pequenas cidades; o estudante, o pai, o familiar, muitas 
V.13, n.1:2017.

vezes, mantêm uma visão imperceptível a todo um processo disciplinar que valoriza os detalhes e as pequenas coisas. Entretanto, para o homem disciplinado as pequenas coisas são importantes. $\mathrm{O}$ discente dentro da escola "Gustavo Dutra" respeita os detalhes, sem deixar de lado as pequenas coisas (SOARES, 2007, p. 32-33).

Lindamar Soares enfatiza que a escola mantinha um controle rigoroso da disciplina, tanto nas salas de aula quanto nas atividades de campo:

Uma leitura detalhada dos livros de registro foi possível identificar uma instituição disciplinar que se valia da observação contínua e diária. O discente era visto em todos os locais da escola desde as salas de aula e até mesmo na horta, na pocilga... As salas de aula eram bem dispostas em filas e existia a organização por etapas, ou seja, da série inicial à série mais elevada. A série inicial ocupava a primeira sala do corredor e assim por diante (SOARES, 2007, p. 39).

Por se tratar de uma escola de grande dimensão territorial, Lindamar Soares nos chama a atenção para a observação da disciplina que era feita por meio de fichas de controle e enfatiza que esse tipo de monitoração era muito valorizado:

A organização, através de fichas de controle de cada aluno, foi muito utilizada na escola de Iniciação Agrícola "Gustavo Dutra". Existia a observância das fichas pelos guardas. Os outros funcionários da instituição e mesmo a direção valorizavam a organização e controle como forma de conhecimento das atuações dos discentes em todas as localizações espaciais, pois, afinal, a escola era muito extensa e tais procedimentos tornavam-se necessários, principalmente na informação da conduta dos alunos nos alojamentos (SOARES, 2007, p. 40).

Toda essa organização tinha uma razão de ser. Os alunos que não cometiam faltas eram elogiados pela direção da escola durante o ato cívico, que acontecia diariamente no pátio de recreio, e eram agraciados com o final de semana livre de qualquer serviço. Já os faltosos se viam na obrigação de saldar as faltas realizando trabalhos nas unidades de produção. Lindamar Soares esclarece que:

As fichas de controle eram utilizadas desde o início de cada manhã, logo após do desfecho do Hino Nacional e da leitura dos avisos. O discente respondia a uma chamada de presença e as ausências eram anotadas. Os presentes eram recompensados com um final de semana livre, os ausentes respondiam outras chamadas nos finais de semana, quando eram obrigados a fazerem atividades extraclasse de trabalho 
V.13, n.1:2017.

duro nas lavouras ou nas próprias instalações físicas (SOARES, 2007, p. 40).

Ainda com relação às penalidades impostas aos alunos, Lindamar Soares não deixa dúvidas quanto à dureza com que eram tratados:

Outro passo disciplinar importante era a procura, no mesmo dia, do aluno faltoso. Em um livro de registro dos guardas foi relatada a fuga de alguns discentes, das áreas de trabalho. Geralmente, os discentes fujões procuravam algum local de lazer. A fuga era rápida e escapava da vista dos controladores, só que no mesmo dia o responsável pelo ato era encontrado e levado para responder pela atitude impensada. A pena, para o desvirtuamento das regras abalizadas pela lei imposta por normativas prescritas em Documentos Internos, era passar outro final de semana no afadigamento do trabalho que passava a ser também um meio de punição e de castigo a todos aqueles que desvirtuassem as regras e normas escolares (SOARES, 2007, p. 41).

Por fim, Lindamar Soares trata da questão do tempo escolar na Escola Gustavo Dutra. Para a pesquisadora

Procura-se utilizar bem o tempo, garantir a qualidade do tempo empregado; um controle ininterrupto, pressão dos fiscais, anulação de tudo o que possa perturbar e distrair, como diz Foucault; trata-se de constituir um tempo integralmente útil. Os discentes da "Gustavo Dutra" começavam cedo com atividades de Educação Física que ajudavam o corpo a aguentar o batente do resto do dia. A merenda reforçada era uma das fórmulas para o corpo estar pronto para os exercícios propícios a uma escola muito similar aos modelos militares. Depois dos ingredientes certos para o início da manhã, os ajustes, necessários para um bom empenho tanto das atividades práticas como teóricas eram tomados, não anulando nada o que fosse necessário para se conseguir um bom aproveitamento escolar diário. Um tempo de boa qualidade, sem defeitos a aproveitar, na época, os mínimos detalhes sem, até mesmo, deixar de começar qualquer atividade fora da hora certa, isto é, no educandário as horas, os minutos, os segundos eram respeitados com rigor. Um modelo muito parecido com a Europa onde nem um minuto é perdido, tudo na hora exata (SOARES, 2007, p. 45).

Ao se esboçar a história de uma instituição educacional, é necessário situar o seu comprometimento no contexto histórico local. O discurso oficial traz o Aprendizado como a escola ideal e aquela que solucionaria o problema maior da agricultura matogrossense: a ausência de técnicas apropriadas para o aumento da produção e, 
V.13, n.1:2017.

consequentemente, do vigor econômico do Estado. Nesse contexto, Justino Magalhães afirma:

Compreender e explicar a existência histórica de uma instituição educativa é, sem deixar de integrá-la na realidade mais ampla que é o sistema educativo, contextualizá-la, implicando no quadro de evolução de uma comunidade e de uma região, é por fim sistematizar e (re) escrever-lhe o itinerário de vida na sua multidimensionalidade, conferindo um sentido histórico (MAGALHÃES, 1999b, p. 2).

Rosinete Reis, em sua dissertação de mestrado, também faz uma descrição que colabora com esta pesquisa:

Ao arremedo do que foram intitulados os primeiros Grupos Escolares de Mato Grosso, criados nas primeiras décadas do Século XX, o Aprendizado Agrícola Gustavo Dutra foi representado como "palácio", local onde alunos, professores e servidores administrativos fixariam suas residências, e instituição onde as "luzes" do saber seriam capazes de transformar filhos de rudes fazendeiros em "príncipes" de um novo tempo que se anunciava. Os seus professores representariam os antigos preceptores, homens e mulheres dotados de cultura e espírito de desprendimento. Os funcionários da instituição, abnegados servidores que, com seu diligente trabalho, manteriam a ordem e rigor necessários ao bom andamento de todas as instalações constitutivas do "palácio". Assim adjetivado, o Aprendizado Agrícola "Gustavo Dutra" deixaria de ser visto como uma escola rural de grande porte, mas passaria a representar local de primeira grandeza, tal qual os "palácios" edificados na zona urbana da Capital (REIS, 2003, p. 87).

Em 22 de janeiro de 1947, por meio do Decreto $\mathrm{n}^{\circ}$ 22.506, Eurico Gaspar Dutra, então Presidente da República, transformou o Aprendizado Agrícola em Escola de Iniciação Agrícola, mantendo a denominação "Gustavo Dutra". Em 05 de novembro de 1956, o Presidente Juscelino Kubitschek, por meio do Decreto ${ }^{\circ} 40.268$, alterou novamente a denominação do estabelecimento para Escola Agrícola “Gustavo Dutra”.

Com o nome de Escola Agrícola, o estabelecimento funcionou até 1964, quando passou a denominar-se Ginásio Agrícola Gustavo Dutra. O Decreto $\mathrm{n}^{\circ} 53.558$ foi assinado pelo então presidente João Goulart em 13 de fevereiro de 1964. Já no ano de 1967, como parte de ampla reforma estrutural do governo, o então presidente Arthur da Costa e Silva transferiu o ginásio para a órbita administrativa do Ministério da Educação e Cultura. O Decreto n. ${ }^{\circ}$ 60.731, de 19 de maio de 1967, foi o Ato 
V.13, n.1:2017.

Administrativo responsável por essa transferência.

O Prof. J. Torquato Jardim, Diretor-Geral do Departamento de Ensino Médio do Ministério da Educação e Cultura, autorizou o funcionamento do curso Técnico em Agropecuária por meio da Portaria nº 21, de 21 de março de 1978. Com a criação de cursos em nível de segundo grau e o evidente desenvolvimento tecnológico, pedagógico e administrativo, o Ginásio Agrícola Gustavo Dutra foi elevado à categoria de Escola Agrotécnica Federal. O Decreto n ${ }^{\circ} 83.935$, de 04 de setembro de 1979, assinado pelo então presidente João Baptista de Oliveira Figueiredo.

Em 16 de agosto de 2002, o então Presidente Fernando Henrique Cardoso, por meio de Decreto, transformou a Escola Agrotécnica Federal de Cuiabá - MT em Centro Federal de Educação Tecnológica - Cefet/Cuiabá, sustentado por critérios técnicos. O Cefet/Cuiabá ganhou nova denominação em 2008, por meio da Lei $\mathrm{n}^{\circ} 11.892$, de 29 de dezembro, quando se transformou em Instituto Federal de Educação, Ciência e Tecnologia do Estado de Mato Grosso - Campus São Vicente.

O Instituto Federal de Educação, Ciência e Tecnologia de Mato Grosso IFMT, criado nos termos da Lei $\mathrm{n}^{\circ}$. 11.892, de 29 de dezembro de 2008, mediante integração do Centro Federal de Educação Tecnológica de Mato Grosso, do Centro Federal de Educação Tecnológica de Cuiabá e da Escola Agrotécnica Federal de Cáceres, é uma instituição de educação superior, básica e profissional, pluricurricular e multicampi, especializada na oferta de educação profissional e tecnológica nas diferentes modalidades de ensino. É uma instituição vinculada ao Ministério da Educação, possui natureza jurídica de autarquia, com autonomia administrativa, patrimonial, financeira, didático-pedagógica e disciplinar.

O IFMT tem no Estado de Mato Grosso, a sua área de atuação geográfica, conta com onze campus em funcionamento e mais três em construção, além da sua Reitoria instalada em Cuiabá. Para efeito da incidência das disposições que regem a regulação, avaliação e supervisão da instituição e dos cursos de educação superior, o IFMT é equiparado às universidades federais.

\section{BIBLIOGRAFIA}

BUFFA, Ester e NOSELLA, Paolo. Industrialização e educação: A Escola 
V.13, n.1:2017.

Profissional de São Carlos - 1932-1971. São Carlos, EdUFSCar, 1988.

MAGALHÃES, Justino. Breve apontamento para a história das instituições educativas. In SANFELICE, José Luís; SAVIANI, Dermeval \& LOMBARDI, José Claudinei. (Orgs.). História da Educação: perspectivas para um intercâmbio internacional. Campinas: Autores Associados, 1999, p. 67-72.

Contributo para a história das instituições educativas - entre a memória e o arquivo. Instituto de Educação e Psicologia, Universidade do Minho, Portugal, 1999.

. Um apontamento metodológico sobre a história das instituições educativas. In SOUZA, C. e CATANI, D. (orgs.). Práticas educativas, culturas escolares, profissão docente. Congresso Luso-brasileiro de História da Educação, 2. São Paulo: Escrituras, 1998, p. 51-68.

A História das instituições educacionais em perspectiva. In GATTI JÚNIOR, Décio; INÁCIO FILHO, Geraldo. História da educação em perspectiva: ensino, pesquisa, produção e novas investigações. São Paulo: Autores Associados: Uberlândia: EdUFU, 2005, p. 97-102.

MARQUES, Abimael Antunes. Aprendizado Agrícola "Gustavo Dutra": seu papel e importância no contexto agrícola de Mato Grosso (1943-1947), Cuiabá: UFMT/IE, Dissertação de Mestrado, 2005.

MARQUES, Abimael Antunes. Histórico do Instituto Federal de Educação, Ciência e Tecnologia de Mato Grosso. Mimeografado. 2013.

NEUVALD, Luciane. O Aprendizado Agrícola “Gustavo Dutra" no Período Populista e o Processo de Modernização da Agricultura de Mato Grosso (1943/1964). Dissertação de Mestrado, UFMT, 1997.

REIS, Rosinete Maria dos. Palácios da Instrução: institucionalização dos Grupos Escolares em Mato Grosso. - Programa de Pós-Graduação em Educação, Universidade Federal de Mato Grosso, Cuiabá, Dissertação de Mestrado, 2003.

; SÁ, Nicanor Palhares. Palácios da instrução: institucionalização dos grupos escolares em Mato Grosso (1910 -1927). Cuiabá: Central de Texto/EdUFMT, 2006. (Coleção coletânea educação e memória. v.3).

SOARES, Lindamar Etelvino Santos. ESCOLA DE INICIAÇÃO AGRÍCOLA "GUSTAVO DUTRA": O poder disciplinar no contexto do ensino agrícola de Mato Grosso (1947-1956). Dissertação de mestrado - Programa de Pós-Graduação em Educação, Universidade Federal de Mato Grosso, Cuiabá, 2007. 